\title{
Slow Titration and Delayed Intensification of Basal Insulin Among Patients with Type 2 Diabetes
}

\author{
Michelle Mocarski, MPH; Jason Yeaw, MPH; Victoria Divino, BA; Mitch DeKoven, MHSA; \\ German Guerrero, MD; Jakob Langer, MSc; and Brian Larsen Thorsted, MSc
}

\begin{abstract}
BACKGROUND: Clinical inertia in type 2 diabetes mellitus (T2DM) refers to the failure of clinicians to intensify therapy when indicated. Many T2DM patients remain suboptimally controlled after initiating basal insulin.

OBJECTIVE: To examine the prevalence of patients treated with basal insulin but in poor glycemic control (hemoglobin A1c $[A 1 \mathrm{c}] \geq 7 \%$ ) after initiation and subsequent treatment intensification patterns and glycemic outcomes in a real-world setting.
\end{abstract}

METHODS: Adults diagnosed with T2DM newly initiating a basal insulin analog (insulin glargine or detemir) from January 2010 to September 2014 were identified in the QuintilesIMS Real-World Data Adjudicated Claims linked to the QuintilesIMS Real-World Data Electronic Medical Records. Patients were previously naive to insulin and glucagon-like peptide-1 receptor agonists (GLP-1 RAs), were persistent on therapy for $\geq 6$ months, and had $\geq 12$ months of continuous health plan enrollment after initiation. First treatment intensification (increase in basal insulin dose [of $\geq 10 \%$ ], addition of bolus insulin, GLP-1 RA, or a new oral antidiabetic drug [OAD]) was assessed among patients in poor glycemic control at 6 months after initiation over the available (minimum $\geq 12$-month) follow-up. Subsequent glycemic outcomes and treatment intensification were assessed. KaplanMeier (KM) analysis evaluated time-to-treatment intensification and time to A1c goal.

RESULTS: Of 427 eligible patients with A1c available at 6 months, $59.3 \%$ were male; mean age was 53.9 years; mean follow-up was 29.4 months; and mean dose of the initiated prescription was 29.6 insulin units (U) (median 24U). Six months after initiating basal insulin, $81.0 \%$ of patients $(n=346)$ remained in poor glycemic control, and mean basal insulin dose was $31.0 \mathrm{U}$ (median $25 \mathrm{U}$ ). Most $(88.4 \% ; n=306)$ of these uncontrolled patients subsequently intensified treatment over the available follow-up. Using KM analysis, these patients intensified treatment in a median of 58 days (range: 17.5 days [GLP-1 RA addition] to 52 days [increase in basal insulin dose]) from the first elevated A1c measurement taken after 6 months, and $72.5 \%$ (GLP-1 RA addition) to $91.1 \%$ (OAD addition) of patients continued to remain in poor glycemic control at 12 months after intensification. Most patients $(66.8 \% ; n=231 / 346)$ first intensified treatment by increasing their basal insulin dose, and mean dose increased to 61.7U (median 38U) at intensification. Six months following basal insulin increase, almost all patients remained on basal insulin therapy and among those with available A1c, $92.1 \%$ (140 of 152) were in poor glycemic control. In the subsequent 12 months, only a third (34\%) of uncontrolled patients added another antihyperglycemic agent.

CONCLUSIONS: The vast majority of patients remained uncontrolled in the 6 months following basal insulin initiation. Basal insulin up-titration was slow and insufficient in the 6 months after initiation, indicating treatment inertia. Subsequently, most patients failed to achieve glycemic targets despite intensification with basal insulin. This finding suggests a substantial unmet need for effective treatment intensification among T2DM patients treated with basal insulin who remain uncontrolled. Improved provider education and guidelines on appropriate intensification are warranted.

J Manag Care Spec Pharm. 2018;24(4):390-400

Copyright $\odot 2018$, Academy of Managed Care Pharmacy. All rights reserved.

\section{What is already known about this subject}

A critical part of diabetes management is adequate glycemic control, which plays a large role in preventing or delaying complications associated with diabetes.

In diabetes, clinical inertia refers to the failure of clinicians to intensify therapy with antihyperglycemic agents in patients who have not reached their recommended glycemic targets despite persistently elevated blood glucose and Alc levels.

Real-world studies have demonstrated that a substantial proportion of patients remain in poor glycemic control following insulin initiation, and the delay in treatment intensification can last several years.

\section{What this study adds}

This study evaluated treatment intensification patterns and glycemic outcomes among type 2 diabetes mellitus (T2DM) patients initiating basal insulin who remained in poor control; provides insight into how basal insulin dose changes; and considers increasing the basal insulin dose as a treatment intensification strategy.

Basal insulin dose increased minimally from initiation to 6 months after initiation, and most patients who were uncontrolled at 6 months subsequently intensified treatment, most often by increasing their basal insulin dose.

Despite intensification, the majority of T2DM patients new to basal insulin failed to achieve glycemic targets, suggesting a substantial unmet need for effective treatment intensification.

T ype 2 diabetes mellitus (T2DM) affects approximately 27 million people in the United States and is associated with substantial costs. ${ }^{1,2}$ A critical part of diabetes management is adequate glycemic control, which plays a large role in preventing or delaying complications associated with diabetes. ${ }^{3}$

Antihyperglycemic agents (AHAs) work by lowering glucose levels in the blood. The American Diabetes Association (ADA) states that a reasonable hemoglobin Alc (Alc) goal for many adults is $<7 \%{ }^{4}$ However, less stringent Alc goals may be appropriate for more complex patients (e.g., history of severe hypoglycemia, limited life expectancy, and advanced complications), and a number of quality measures evaluate poor control using Alc thresholds of $8 \%$ or $9 \%,{ }^{5,6}$ Because of the progressive deterioration of glucose control in T2DM, many patients will eventually require and benefit from insulin therapy. ${ }^{7,8}$ 
According to the ADA, insulin should be considered in a combination regimen when hyperglycemia is severe, especially in symptomatic patients, and insulin therapy should not be delayed in patients who are not achieving glycemic goals. ${ }^{7}$ Basal insulin may be incorporated into a dual therapy regimen with metformin or a triple therapy regimen with metformin and another oral antidiabetic drug (OAD) class or a glucagon-like peptide-1 receptor agonist (GLP-1 RA). ${ }^{7}$

Patients optimally titrated on basal insulin who continue to have Alc above target should consider advancing to combination injectable therapy. Guidelines suggest GLP-1 RA or bolus insulin can be used alongside basal insulin. ${ }^{7}$ Before initiation of combination injectable therapy, addition of a new AHA is recommended if Alc targets are not achieved after approximately 3 months on a regimen. ${ }^{7}$ However, specific recommendations on timing of intensification of insulin in combination injectable therapy are lacking in guidelines.

In diabetes, clinical inertia refers to the failure of clinicians to intensify AHA therapy in patients who have not reached their recommended glycemic targets despite persistently elevated blood glucose and Alc levels. ${ }^{9}$ Clinical inertia could result in severe clinical consequences such as increased risk of irreversible, diabetes-related complications and cardiovascular events. ${ }^{10-12}$ Poor glycemic control is also associated with increased costs. ${ }^{13}$ Sustained glycemic control associated with a reduction in the incidence of diabetes complications and morbidity may be an important contributor to reduced costs. ${ }^{14}$

Clinical inertia has been documented among patients with T2DM treated with OADs. ${ }^{15-20}$ However, the occurrence and impact of clinical inertia among patients treated with basal insulin is not well understood. ${ }^{21-25}$ Previous studies have found that the majority of patients who are uncontrolled on insulin fail to intensify treatment. ${ }^{21,22,24}$ For those patients who do intensify insulin treatment, there is often a substantial delay. ${ }^{23,25}$

The extent of treatment inertia among patients treated with basal insulin is unknown, as previous studies defined treatment intensification as addition of another AHA. They did not consider an increase in basal insulin as a treatment intensification strategy due to limitations of the data sources used to capture basal insulin dose. There is also a lack of insight into how the dose of basal insulin changes after patients initiate basal insulin, particularly among patients who remain uncontrolled.

The objective of this study was to examine treatment intensification patterns among patients with T2DM initiating basal insulin in the United States in a real-world setting. Specific objectives were to assess the prevalence of uncontrolled patients on basal insulin (using a threshold of $A l c \geq 7 \%$ ) and to evaluate subsequent treatment intensification patterns while uncontrolled and subsequent glycemic outcomes.

\section{Methods}

\section{Study Design and Data Source}

A retrospective cohort study was conducted to assess real-world treatment intensification patterns among patients with T2DM initiating basal insulin. This study used a linked patient population from the QuintilesIMS Real-World Data (RWD) Adjudicated Claims and the QuintilesIMS RWD Electronic Medical Records (EMR). Data from the QuintilesIMS RWD Adjudicated Claims from July 2009 through September 2015 were used to evaluate patients with T2DM initiating basal insulin. Patients were then linked to the QuintilesIMS RWD EMR to identify the subset with available Alc lab values.

The QuintilesIMS RWD Adjudicated Claims consists of fully adjudicated, longitudinal medical and pharmaceutical claims for more than 150 million unique patients. Standard fields include inpatient and outpatient diagnoses and procedures and retail and mail order prescription records. The QuintilesIMS RWD EMR comprises approximately 50 million patient records that are collected from 40,000 physicians from large practices and physician networks. Key information includes clinical details and lab tests performed and results (e.g., Alc, body mass index [BMI], weight) as well as ethnicity.

\section{Study Population}

All patients who filled a prescription for a basal insulin analog (insulin glargine [Lantus] or insulin detemir [Levemir]) between January 1, 2010, and September 30, 2014, were evaluated for study eligibility. The first prescription claim for a basal insulin during the selection window defined the index basal insulin therapy and the date was considered the index date. Patients were included if they met all of the eligibility criteria (Figure 1), which included the following:

- Aged $\geq 18$ years old at index date

- Continuous health plan enrollment $(C E) \geq 6$ months before the index date (the pre-index or baseline period) and $\geq 12$ months following the index date (the post-index or follow-up period; variable [minimum 12-month] follow-up was used)

- $\geq 1$ diagnosis for T2DM in the 6 months pre-index

- Persistent on the index basal insulin therapy for $\geq 6$ months post-index

- Without $\geq 1$ prescription for any insulin or GLP-1 RA in the 6 months pre-index (i.e., newly initiating insulin and without GLP-1 RA use, to exclude patients with previous injectable AHA therapy use, which may affect the decision to intensify treatment)

- Without use of a new AHA class (not used in the 6 months pre-index) or nonbasal insulin in the 6 months post-index (to allow a 6-month period after initiation for patients to stabilize their basal insulin dose without a new AHA addition)

- Patients who met all eligibility criteria in QuintilesIMS RWD Adjudicated Claims were then linked to QuintilesIMS RWD EMR to evaluate glycemic control at 6 months post-index (measured between 180 and 359 days postindex). Subsequent treatment intensification patterns and glycemic outcomes were assessed among the subset of patients who were uncontrolled or in poor 


\section{FIGURE 1 Sample Selection Flowchart}

Patients with $\geq 1$ pharmacy claim for a basal insulin analog between January 1, 2010, and September 30, 2014 $\mathrm{N}=820,739(100.0 \%)$

$\geq 180$ days $C E$ pre-index and $\geq 360$ days CE post-index $\mathrm{n}=357,016(43.5 \%)$

Without use of insulin or GLP-1 RA in the 6 months pre-index and not initiating $\geq 1$ insulin on the index date $n=125,755(15.3 \%)$

Persistent on the index basal insulin therapy $\geq 6$ months post-index and with $\geq 1$ refill of the index therapy $n=83,220(10.1 \%)$

Without use of a new AHA class or nonbasal insulin during 6 months post-index or use of NPH insulin, premix insulin, or new use of amylin analogue at any time over the study follow-up $n=47,388(5.8 \%)$

$\begin{gathered}\text { Aged } \geq 18 \text { years at index, with } \geq 1 \text { T2DM diagnosis in the } \\ 6 \text { months pre-index; without diagnoses of T1DM, } \\ \text { pregnancy, or gestational diabetes during the study period; } \\ \text { and without incomplete/invalid data } \\ \mathrm{n}=23,260(2.8 \%)\end{gathered}$
$\downarrow$
Overall Sample in PharMetrics Plus
$\mathrm{n}=23,260$

glycemic control, defined using a threshold of Alc $\geq 7 \%$. Study subgroups of interest were (a) patients in poor glycemic control at 6 months post-index (between 180 and 359 days post-index), (b) patients who first intensified by increased basal insulin dose, and (c) patients in poor glycemic control after 6 months following increased basal insulin dose.

\section{Study Measures}

Baseline demographic and clinical characteristics were evaluated for the overall study sample of patients newly initiating basal insulin from QuintilesIMS RWD Adjudicated Claims, as well as the study subgroups of interest for the study outcomes (Outcomes \#1 to \#3). Demographic characteristics were measured at the index date. Clinical characteristics included dose of the index basal insulin prescription (calculated; measured as quantity/days to next refill [the days supply field is not reliable using billing claims data ${ }^{26}$ ); physician specialty associated with the index date; Charlson Comorbidity Index score (excluding diabetes; the Dartmouth-Manitoba version, for use with administrative claims data ${ }^{27,28}$ ); and relevant comorbidities of interest and pre-index AHA use (codes used in this analysis for comorbidities and AHAs are available from the authors upon request). Baseline laboratory results (Alc, BMI, weight; measured from 7 days before to 45 days after the index date) and ethnicity were included as available from QuintilesIMS RWD EMR.

Patients were considered uncontrolled or in poor glycemic control based on a threshold of Alc $\geq 7 \%$ at 6 months postindex (between 180 and 359 days post-index). Because a target of Alc $<7 \%$ may not be appropriate for all T2DM patients, sensitivity analyses were conducted using less stringent Alc targets of $<8 \%$ and $\leq 9 \%$ to assess the effect of the poor glycemic control definition on Outcome \#1. Time in poor glycemic control was measured from first elevated Alc measurement (Alc $\geq 7 \%$ ) taken later than 6 months after initiation of basal insulin treatment (the allowed period for basal insulin titration), until the first of either treatment intensification or censoring.

Patients were censored at the first occurrence of (a) drop in Alc below target, (b) discontinuation of basal insulin therapy, (c) death (discharge of death observed in the inpatient setting), (d) end of enrollment in QuintilesIMS RWD Adjudicated Claims, or (e) end of study period (September 30, 2015).

Discontinuation of basal insulin was evaluated using a previously published method from a study that evaluated clinical and economic outcomes in patients initiating insulin glargine or exenatide twice-daily using administrative claims data. ${ }^{29}$ Basal insulin prescriptions received on the index date were stratified by prescribed quantity. The 90th percentile of time to next refill defined the allowed gap for a specific quantity. The allowed gap was assigned to each claim over the follow-up based on the quantity dispensed, and discontinuation was defined as a gap in therapy greater than the allowed gap.

\section{Study Outcomes}

There were several study outcomes of interest. For Outcome \#1, patients in poor glycemic control at 6 months post-index (between 180 and 359 days post-index) were identified. The stable basal insulin dose was reported for these patients as the dose reached during the initial 6-month titration period. This dose was measured as (quantity from the last prescription before 180 days post-index $) \div$ (days to next refill). 


\section{TABLE 1 Baseline Demographic and Clinical Characteristics for the Overall Sample and Study Subgroups}

\begin{tabular}{|c|c|c|c|c|c|c|c|c|c|c|}
\hline \multirow[b]{3}{*}{ Characteristic } & \multicolumn{2}{|c|}{ Overall } & \multicolumn{2}{|c|}{$\begin{array}{c}\text { With Available } \\
\text { 6-Month Alc }\end{array}$} & \multicolumn{2}{|c|}{$\begin{array}{c}\text { With Poor Glycemic } \\
\text { Control (Alc } \geq 7 \% \text { ) at } \\
6 \text { Months }\end{array}$} & \multicolumn{2}{|c|}{$\begin{array}{l}\text { First Intensified } \\
\text { by Increased Basal } \\
\text { Insulin Dose }\end{array}$} & \multicolumn{2}{|c|}{$\begin{array}{c}\text { In Poor Glycemic } \\
\text { Control (Alc } \geq 7 \% \text { ) } \\
\text { After } 6 \text { Months of } \\
\text { Increased Basal } \\
\text { Insulin Dose }\end{array}$} \\
\hline & \multicolumn{2}{|c|}{$\mathrm{N}=23,260$} & \multicolumn{2}{|c|}{$\mathrm{n}=427$} & \multicolumn{2}{|c|}{$\mathrm{n}=346$} & \multicolumn{2}{|c|}{$\mathrm{n}=231$} & \multicolumn{2}{|c|}{$\mathrm{n}=151$} \\
\hline & $\mathrm{n}$ & $\%$ & $\mathrm{n}$ & $\%$ & $\mathrm{n}$ & $\%$ & $\mathrm{n}$ & $\%$ & $\mathrm{n}$ & $\%$ \\
\hline \multicolumn{11}{|l|}{ Age (years) } \\
\hline Mean \pm SD & \multicolumn{2}{|c|}{$53.6 \pm 8.0$} & \multicolumn{2}{|c|}{$53.9 \pm 8.3$} & \multicolumn{2}{|c|}{$54.1 \pm 8.0$} & \multicolumn{2}{|c|}{$54.7 \pm 7.9$} & \multicolumn{2}{|c|}{$54.3 \pm 7.7$} \\
\hline Median & \multicolumn{2}{|c|}{55} & & & & & & & & \\
\hline Male gender & 13,603 & $(58.5)$ & 253 & $(59.3)$ & 204 & $(59.0)$ & 139 & $(60.2)$ & 96 & $(63.6)$ \\
\hline Ethnicity & 2,798 & $(12.0)$ & 427 & $(100.0)$ & 346 & $(100.0)$ & 231 & $(100.0)$ & 151 & $(100.0)$ \\
\hline Caucasian & 1,370 & $(5.9)$ & 335 & $(78.5)$ & 271 & $(78.3)$ & 185 & $(80.1)$ & 119 & (78.8) \\
\hline Black & 91 & $(0.4)$ & 19 & (4.4) & 14 & $(4.0)$ & 7 & $(3.0)$ & 6 & $(4.0)$ \\
\hline Asian & 17 & $(0.1)$ & 5 & $(1.2)$ & 5 & (1.4) & 0 & $(0.0)$ & 0 & $(0.0)$ \\
\hline Other/unknown & 21,782 & (93.6) & 68 & (15.9) & 56 & $(16.2)$ & 39 & $(16.9)$ & 26 & $(17.2)$ \\
\hline Payer type & & & & & & & & & & \\
\hline Commercial & 13,902 & $(59.8)$ & 197 & $(46.1)$ & 158 & $(45.7)$ & 110 & $(47.6)$ & 74 & $(49.0)$ \\
\hline Medicaid & 915 & (3.9) & 4 & $(0.9)$ & 3 & $(0.9)$ & 1 & $(0.4)$ & 1 & $(0.7)$ \\
\hline Medicare risk & 408 & (1.8) & 23 & $(5.4)$ & 19 & $(5.5)$ & 13 & (5.6) & 5 & (3.3) \\
\hline Self-insured & 7,953 & $(34.2)$ & 203 & $(47.5)$ & 166 & $(48.0)$ & 107 & (46.3) & 71 & $(47.0)$ \\
\hline Unknown & 82 & $(0.4)$ & 0 & $(0.0)$ & 0 & $(0.0)$ & 0 & $(0.0)$ & 0 & $(0.0)$ \\
\hline Region & & & & & & & & & & \\
\hline Northeast & 4,921 & $(21.2)$ & 154 & $(36.1)$ & 121 & $(35.0)$ & 82 & (35.5) & 53 & $(35.1)$ \\
\hline Midwest & 6,818 & $(29.3)$ & 107 & $(25.1)$ & 87 & $(25.1)$ & 61 & (26.4) & 46 & $(30.5)$ \\
\hline South & 8,715 & $(37.5)$ & 119 & $(27.9)$ & 96 & $(27.7)$ & 61 & $(26.4)$ & 39 & $(25.8)$ \\
\hline West & 2,806 & (12.1) & 47 & (11.0) & 42 & (12.1) & 27 & (11.7) & 13 & (8.6) \\
\hline Basal insulin dose of the index & ription & & & & & & & & & \\
\hline Mean \pm SD & 35 & & & 38.8 & & 41.4 & & 12.3 & & 11.3 \\
\hline Median & & & & & & & & & & \\
\hline Physician specialty & & & & & & & & & & \\
\hline Endocrinologist & 703 & $(3.0)$ & 16 & $(3.7)$ & 8 & $(2.3)$ & 5 & $(2.2)$ & 4 & $(2.6)$ \\
\hline Primary care (GP/FM/IM) & 9,802 & $(42.1)$ & 146 & $(34.2)$ & 118 & $(34.1)$ & 78 & $(33.8)$ & 51 & $(33.8)$ \\
\hline Hospitalist & 2,619 & (11.3) & 67 & (15.7) & 54 & (15.6) & 40 & $(17.3)$ & 24 & $(15.9)$ \\
\hline Other & 10,136 & $(43.6)$ & 198 & $(46.4)$ & 166 & $(48.0)$ & 108 & $(46.8)$ & 72 & $(47.7)$ \\
\hline $\mathrm{CCI}^{\mathrm{a}}$ & & & & & & & & & & \\
\hline Mean \pm SD & 0.4 & & & & & 0.8) & & (0.9) & & 0.9) \\
\hline Median & & & & & & & & & & \\
\hline DCSI & & & & & & & & & & \\
\hline Mean \pm SD & 0.3 & & & & & 0.8) & & (0.9) & & $0.7)$ \\
\hline Median & & & & & & & & & & \\
\hline Frequent ( $\geq 10 \%$ ) comorbidities & terest & & & & & & & & & \\
\hline Cardiovascular disease ${ }^{\mathrm{b}}$ & 16,006 & $(68.8)$ & 301 & $(70.5)$ & 246 & $(71.1)$ & 161 & $(69.7)$ & 113 & $(74.8)$ \\
\hline Coronary artery disease & 2,386 & $(10.3)$ & 50 & $(11.7)$ & 39 & (11.3) & 24 & (10.4) & 17 & (11.3) \\
\hline Depression & 1,807 & $(7.8)$ & 43 & $(10.1)$ & 36 & $(10.4)$ & 21 & $(9.1)$ & 12 & $(7.9)$ \\
\hline Dyslipidemia & 15,240 & $(65.5)$ & 311 & (72.8) & 255 & (73.7) & 171 & $(74.0)$ & 115 & $(76.2)$ \\
\hline Hypertension & 15,380 & $(66.1)$ & 289 & $(67.7)$ & 236 & $(68.2)$ & 154 & $(66.7)$ & 109 & $(72.2)$ \\
\hline Frequent ( $\geq 10 \%$ ) AHA classes & & & & & & & & & & \\
\hline Biguanides & 14,901 & $(64.1)$ & 289 & $(67.7)$ & 237 & $(68.5)$ & 157 & $(68.0)$ & 106 & $(70.2)$ \\
\hline DPP-4 inhibitors & 5,757 & (24.8) & 147 & (34.4) & 127 & $(36.7)$ & 82 & $(35.5)$ & 63 & $(41.7)$ \\
\hline Fixed-dose combination orals & 4,090 & (17.6) & 77 & (18.0) & 69 & (19.9) & 48 & $(20.8)$ & 30 & (19.9) \\
\hline Sulfonylureas & 12,457 & $(53.6)$ & 247 & $(57.8)$ & 213 & $(61.6)$ & 140 & $(60.6)$ & 89 & $(58.9)$ \\
\hline TZDs & 3,517 & (15.1) & 68 & (15.9) & 53 & (15.3) & 35 & $(15.2)$ & 26 & $(17.2)$ \\
\hline AHA classes used per patient & & & & & & & & & & \\
\hline Mean \pm SD & 1.8 & & & & & 1.0) & & (0.9) & & 0.9) \\
\hline Median & & & & & & & & & & \\
\hline
\end{tabular}




\begin{tabular}{|c|c|c|c|c|c|c|c|c|c|c|}
\hline \multirow[b]{3}{*}{ Characteristic } & \multicolumn{2}{|c|}{ Overall } & \multicolumn{2}{|c|}{$\begin{array}{c}\text { With Available } \\
\text { 6-Month Alc }\end{array}$} & \multicolumn{2}{|c|}{$\begin{array}{c}\text { With Poor Glycemic } \\
\text { Control (Alc } \geq 7 \% \text { ) at } \\
6 \text { Months }\end{array}$} & \multicolumn{2}{|c|}{$\begin{array}{l}\text { First Intensified } \\
\text { by Increased Basal } \\
\text { Insulin Dose }\end{array}$} & \multicolumn{2}{|c|}{$\begin{array}{l}\text { In Poor Glycemic } \\
\text { Control (Alc } \geq 7 \%) \\
\text { After } 6 \text { Months of } \\
\text { Increased Basal } \\
\text { Insulin Dose }\end{array}$} \\
\hline & \multicolumn{2}{|c|}{$\mathrm{N}=23,260$} & \multicolumn{2}{|c|}{$\mathrm{n}=427$} & \multicolumn{2}{|c|}{$\mathrm{n}=346$} & \multicolumn{2}{|c|}{$\mathrm{n}=231$} & \multicolumn{2}{|c|}{$\mathrm{n}=151$} \\
\hline & $\mathrm{n}$ & $\%$ & $\mathrm{n}$ & $\%$ & $\mathrm{n}$ & $\%$ & $\mathrm{n}$ & $\%$ & $\mathrm{n}$ & $\%$ \\
\hline Alc (mmol/mol \%) & 234 & (1.0) & 147 & $(34.4)$ & 118 & $(34.1)$ & 78 & (33.8) & 55 & (36.4) \\
\hline $6.0-6.9$ & 6 & $(0.0)$ & 4 & $(0.9)$ & 2 & $(0.6)$ & 1 & $(0.4)$ & 1 & $(0.7)$ \\
\hline $7.0-7.9$ & 34 & $(0.1)$ & 23 & $(5.4)$ & 18 & $(5.2)$ & 14 & $(6.1)$ & 12 & $(7.9)$ \\
\hline $8.0-9.0$ & 50 & $(0.2)$ & 35 & $(8.2)$ & 26 & $(7.5)$ & 16 & $(6.9)$ & 10 & $(6.6)$ \\
\hline$>9.0$ & 144 & $(0.6)$ & 85 & (19.9) & 72 & $(20.8)$ & 47 & $(20.3)$ & 32 & $(21.2)$ \\
\hline Mean \pm SD & \multicolumn{2}{|c|}{$9.7 \pm(1.8)$} & \multicolumn{2}{|c|}{$9.5 \pm(1.8)$} & \multicolumn{2}{|c|}{$9.6 \pm(1.7)$} & \multicolumn{2}{|c|}{$9.6 \pm(1.8)$} & \multicolumn{2}{|c|}{$9.5 \pm(1.7)$} \\
\hline Median & \multicolumn{2}{|c|}{9} & \multicolumn{2}{|c|}{9} & \multicolumn{2}{|c|}{9} & \multicolumn{2}{|c|}{9} & \multicolumn{2}{|c|}{9} \\
\hline BMI $\left(\mathrm{kg} / \mathrm{m}^{2}\right)$ & 496 & (2.1) & 257 & $(60.2)$ & 207 & (59.8) & 144 & (62.3) & 92 & $(60.9)$ \\
\hline Mean \pm SD & \multicolumn{2}{|c|}{$34.8 \pm(7.1)$} & \multicolumn{2}{|c|}{$35.2 \pm(7.3)$} & \multicolumn{2}{|c|}{$35.1 \pm(7.3)$} & \multicolumn{2}{|c|}{$34.7 \pm(7.6)$} & \multicolumn{2}{|c|}{$34.9 \pm(7.8)$} \\
\hline Median & \multicolumn{2}{|c|}{34} & \multicolumn{2}{|c|}{35} & \multicolumn{2}{|c|}{35} & \multicolumn{2}{|c|}{34} & \multicolumn{2}{|c|}{34} \\
\hline Weight (kg) & 536 & $(2.3)$ & 282 & $(66.0)$ & 225 & $(65.0)$ & 156 & $(67.5)$ & 98 & $(64.9)$ \\
\hline Mean \pm SD & \multicolumn{2}{|c|}{$103.2 \pm(24.0)$} & \multicolumn{2}{|c|}{$103.2 \pm(24.1)$} & \multicolumn{2}{|c|}{$103.9 \pm(22.9)$} & \multicolumn{2}{|c|}{$102.8 \pm(22.6)$} & \multicolumn{2}{|c|}{$103.9 \pm(22.5)$} \\
\hline Median & & & & & & & & & & \\
\hline
\end{tabular}

${ }^{a}$ CCI excludes diabetes, as it is the exposure of interest.

${ }^{b}$ Cardiovascular disease is not limited to but includes the separately reported categories of cardiac dysrhythmia, congestive heart failure, coronary artery disease, hypertension, and myocardial infarction.

Alc =hemoglobin Alc; $A H A=$ antihyperglycemic agent; BMI=body mass index; $C C I=$ Charlson Comorbidity Index; DCSI=Diabetes Complication Severity Index; $D P P-4=$ dipeptidyl peptidase-4; $F P=$ family practice; $G P=$ general practice; $I M=$ internal medicine; $S D=$ standard deviation; $T Z D=$ thiazolidinedione

The occurrence of the first treatment intensification was assessed among uncontrolled patients, starting after the first elevated 6-month Alc measurement. Four intensification types were evaluated: (1) calculated increase in basal insulin dose, (2) addition of bolus insulin, (3) addition of a GLP-1 RA, and (4) addition of a new OAD (not used in the 6 months pre-index). The latter treatment intensification types were determined based on observed prescription fills (for a new AHA), while increase in basal insulin dose was calculated because prescribed dose was not recorded in the data sources used. Increase in basal insulin dose was defined by a basal insulin prescription with a calculated daily dose that increased by $10 \%$ or more compared with the daily dose of the prior prescription (number of units prescribed $\div$ time [in days] between 2 consecutive prescriptions). This method is consistent with ADA guidelines that recommend adjustment of basal insulin by 10\%-15\% to reach fasting blood glucose target. ${ }^{7}$ In the sensitivity analyses, a 10 -unit increase was used to define increase in basal insulin dose.

For Outcome \#2, patients who first intensified treatment with an increase in basal insulin dose were identified. The stable basal insulin dose at 6 months was reported, as was the dose reached when basal insulin treatment was intensified (i.e., the dose of the prescription that was $\geq 10 \%$ higher than the previous prescription).

For Outcome \#3, patients who were persistent on basal insulin therapy (without discontinuation) 6 months after increasing the dose of basal insulin and who remained in poor glycemic control were identified. Addition of another AHA was assessed, starting from the first elevated Alc measurement (Alc $\geq 7 \%$ ) taken within 6 months following the increase in basal insulin dose.

Finally, for Outcome \#4, a secondary analysis, discontinuation of basal insulin therapy was evaluated among the overall sample of basal insulin initiators. Discontinuation (at exact time points) was assessed at 12 months post-index, and at 24 , 36 , and 48 months post-index, among patients with 24,36 , and 48 months of $\mathrm{CE}$, respectively.

\section{Statistical Analysis}

Descriptive statistics were used to describe frequency and percentage distributions for categorical variables. Continuous and count variables were described using mean, standard deviation (SD), and median. Kaplan-Meier (KM) methods of survival analysis were used to investigate outcomes in which patients had variable follow-up (CE), as it takes into account those lost to follow-up (censored). KM analyses were used to evaluate the intensification outcomes of time from first assessment of elevated Alc measurement taken after 6 months post-index to treatment intensification and time from date of treatment intensification to achieving glycemic control (Outcome \#1). For patients who first intensified treatment by increasing their basal insulin dose, time from first assessment of poor control within 6 months following treatment intensification to addition of a new AHA was also evaluated (Outcome \#3). All analyses were performed using SAS software package 9.3 (SAS Institute, Cary, NC). 
TABLE 2 Treatment Intensification over the Follow-up: Patients with Poor Glycemic Control at 6 Months Post-Index

\begin{tabular}{|c|c|c|c|c|c|c|c|c|}
\hline \multirow{5}{*}{ 6-Month Alc } & & & \multicolumn{6}{|c|}{ Sensitivity Analysis } \\
\hline & & & \multicolumn{4}{|c|}{ Alc Threshold } & \multicolumn{2}{|c|}{$\begin{array}{l}\text { 10-Unit Basal Insulin } \\
\text { Increase }\end{array}$} \\
\hline & \multicolumn{2}{|c|}{ Alc $\geq 7 \%$} & \multicolumn{2}{|c|}{ Alc $\geq 8 \%$} & \multicolumn{2}{|c|}{ Alc $>9 \%$} & \multicolumn{2}{|c|}{$A l c \geq 7 \%$} \\
\hline & \multicolumn{2}{|c|}{$\mathrm{n}=346$} & \multicolumn{2}{|c|}{$\mathrm{n}=221$} & \multicolumn{2}{|c|}{$\mathrm{n}=116$} & \multicolumn{2}{|c|}{$\mathrm{n}=346$} \\
\hline & $\mathrm{n}$ & $\%$ & $\mathrm{n}$ & $\%$ & $\mathrm{n}$ & $\%$ & $\mathrm{n}$ & $\%$ \\
\hline \multicolumn{9}{|l|}{ Any time after 6 months post-index } \\
\hline With treatment intensification & 306 & 88.4 & 195 & 88.2 & 101 & 87.1 & 263 & 76.0 \\
\hline \multicolumn{9}{|l|}{ First intensification type } \\
\hline Increase in basal insulin dose & 231 & 66.8 & 143 & 64.7 & 70 & 60.3 & 167 & 48.3 \\
\hline Addition of bolus insulin & 27 & 7.8 & 21 & 9.5 & 12 & 10.3 & 35 & 10.1 \\
\hline Addition of GLP-1 RA & 16 & 4.6 & 9 & 4.1 & 5 & 4.3 & 19 & 5.5 \\
\hline Addition of OAD & 24 & 6.9 & 14 & 6.3 & 8 & 6.9 & 34 & 9.8 \\
\hline Addition of $>1$ AHA & 8 & 2.3 & 8 & 3.6 & 6 & 5.2 & 8 & 2.3 \\
\hline Censored & 40 & 11.6 & 26 & 11.8 & 15 & 12.9 & 83 & 24.0 \\
\hline \multicolumn{9}{|l|}{ At 12 months post-index } \\
\hline With treatment intensification & 238 & 68.8 & 149 & 67.4 & 78 & 67.2 & 164 & 47.4 \\
\hline \multicolumn{9}{|l|}{ First intensification type } \\
\hline Increase in basal insulin dose & 180 & 52.0 & 108 & 48.9 & 53 & 45.7 & 97 & 28.0 \\
\hline Addition of bolus insulin & 20 & 5.8 & 16 & 7.2 & 10 & 8.6 & 24 & 6.9 \\
\hline Addition of GLP-1 RA & 12 & 3.5 & 7 & 3.2 & 4 & 3.4 & 14 & 4.0 \\
\hline Addition of OAD & 18 & 5.2 & 10 & 4.5 & 5 & 4.3 & 21 & 6.1 \\
\hline Addition of $>1$ AHA & 8 & 2.3 & 8 & 3.6 & 6 & 5.2 & 8 & 2.3 \\
\hline Censored & 108 & 31.2 & 72 & 32.6 & 38 & 32.8 & 182 & 52.6 \\
\hline End of study data & 104 & 30.1 & 69 & 31.2 & 35 & 30.2 & 174 & 50.3 \\
\hline
\end{tabular}

\section{Results}

\section{Study Population}

A total of 820,739 patients were identified in QuintilesIMS RWD Adjudicated Claims with a pharmacy claim for a basal insulin analog between January 2010 and September 2014. The overall sample of patients initiating basal insulin consisted of 23,260 (2.8\%) patients who met the study eligibility criteria (Figure 1).

Of 23,260 patients, only $427(1.8 \%)$ had available Alc measurements at 6 months post-index (between 180 and 359 days post-index; linked to QuintilesIMS RWD EMR) and constituted the sample with available 6-month Alc, among whom the majority of patients $(81.0 \% ; \mathrm{n}=346)$ were in poor glycemic control $(\geq 7 \%)$. Half of the patients $(51.8 \%$; $n=221)$ had poor glycemic control defined as Alc $\geq 8 \%$, while $27.2 \%(n=116)$ had poor glycemic control defined as Alc $>9 \%$.

\section{Baseline Characteristics}

Baseline characteristics were generally similar between the overall sample of patients initiating basal insulin $(n=23,260)$ and the different subsets for Outcomes \#1 to \#3 (Table 1).

\section{First Treatment Intensification Outcomes}

For Outcome \#1, treatment intensification outcomes were assessed among patients in poor glycemic control at 6 months post-index $(\mathrm{n}=346)$. For these patients, mean stable basal insulin dose at 6 months increased to 31.0 insulin units (U; SD 20U) with median 25U. Most patients (88.4\%) subsequently intensified treatment intensification over the available follow-up. The majority (66.8\%) first intensified by increasing the basal insulin dose, while $7.8 \%$ added bolus insulin (Table 2).

The proportion of patients intensifying treatment increased with time from initiation. By 12 months post-index, $68.8 \%$ of the sample for Outcome \#1 $(n=238)$ experienced treatment intensification. Half of the sample for Outcome \#1 (52.0\%) first intensified by increasing the basal insulin dose, while $5.8 \%$ added bolus insulin (Table 2). Among patients with $\geq 24$-month follow-up $(n=194)$, almost all $(93.3 \%, n=181)$ experienced treatment intensification by 24 months post-index (data not shown). The majority $(73.7 \%, \mathrm{n}=143)$ first intensified by increasing the basal insulin dose, while 9.8\% $(n=19)$ added bolus insulin.

In the sensitivity analysis, the effect of the poor glycemic control definition at 6 months on occurrence of treatment intensification by 12 months post-index was assessed (Table 2). Outcomes were similar, with a slight trend toward addition of bolus insulin. Using Alc $\geq 8 \%$ to define poor glycemic control, $67.4 \%$ experienced treatment intensification by 


\section{FIGURE 2 Kaplan-Meier Analysis of Time from Initiation to Treatment Intensification: Patients with Poor} Glycemic Control at 6 Months Post-Index

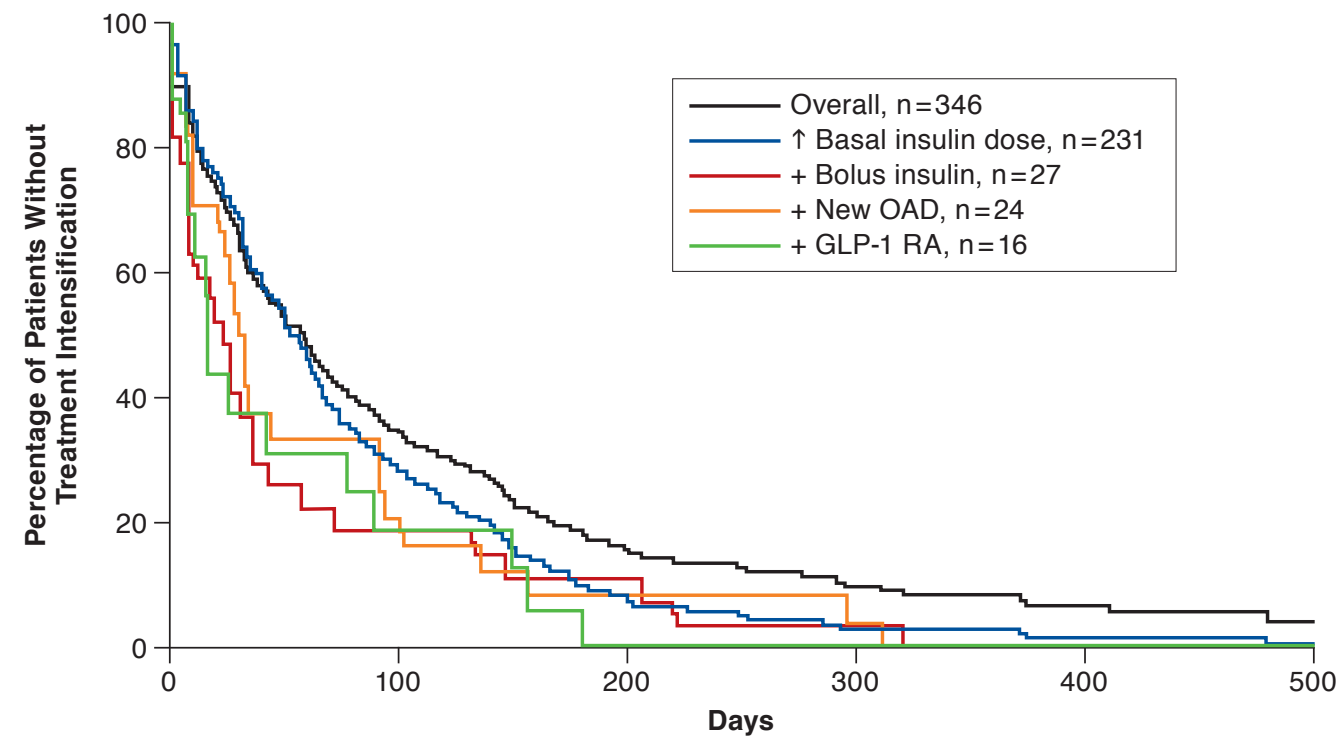

Note: Day $0=$ First elevated Alc measurement $(A 1 c \geq 7 \%)$ taken later than 6 months after initiation of basal insulin treatment.

aPoor glycemic control $=A 1 c \geq 7 \%$.

Alc =hemoglobin A1c; GLP-1 RA= glucagon-like peptide-1 receptor agonist; OAD=oral antidiabetic drug.

12 months post-index, and $7.2 \%$ first intensified by adding bolus insulin. Using Alc > 9\% to define poor glycemic control, $67.2 \%$ experienced treatment intensification and $8.6 \%$ first intensified by adding bolus insulin. Results were highly sensitive to the definition for increase in basal insulin dose (Table 2). When a 10-unit increase in dose was used to define an increase in basal insulin dose, fewer patients experienced treatment intensification. Half of the patients (47.4\%) experienced treatment intensification by 12 months post-index: $28.0 \%$ first intensified by increasing the basal insulin dose, while 6.9\% added bolus insulin (Table 2).

KM analyses showed uncontrolled patients intensified treatment in a median of 58 days (95\% confidence intervals $[\mathrm{CIs}]=45-67)$ from the first elevated Alc measurement in the 6 months post-index. Time to intensification ranged from a median of 17.5 days (95\% CI=9-77) (addition of GLP-1 RA) to 52 days (95\% CI=42-62; increase in basal insulin dose; Figure 2). Despite treatment intensification, KM analysis demonstrated that the vast majority of patients remained in poor glycemic control following the date of treatment intensification (see Appendix, available in online article). By 12 months postintensification, between $72.5 \%$ (addition of GLP-1 RA) and 91.1\% (addition of OAD) of patients had not achieved glycemic control. Small sample sizes for patients who first intensified by adding another AHA limited comparisons by treatment intensification type.

\section{Outcomes After First Intensification of Basal Insulin Dose Increase}

For Outcome \#2, among patients who first intensified by increasing the basal insulin dose $(n=231)$, the mean (SD) basal insulin dose of the index prescription was $25.8 \mathrm{U}$ (12.3U) with median 23U. At 6 months post-index, this dose increased to a mean of $30.4 \mathrm{U}$ (19.8U) with median 24U. At the date of intensification, this dose increased to a mean of $61.7 \mathrm{U}$ (176.8) with median 38U.

For Outcome \#3, in the 6 months following intensification, almost all patients remained on basal insulin therapy (217 of 231), and 152 had Alc available. The vast majority of those with Alc available (92.1\%) remained in poor glycemic control in the 6 months after intensification. In KM analysis, among patients persistent on basal insulin at the first elevated Alc measurement $(\mathrm{Alc} \geq 7 \%)$ taken within 6 months following the date of intensification ( $\mathrm{n}=151)$, only $33.8 \%$ added an AHA within 12 months of that measurement (Figure 3).

\section{Basal Insulin Discontinuation}

For Outcome \#4, in the secondary analysis of basal insulin discontinuation among the overall sample of basal insulin initiators $(n=23,260), 26.5 \%(n=6,158)$ discontinued basal insulin by 12 months post-index. Discontinuation rates increased with time, and rates were $47.5 \%(6,146$ of 12,942$)$, $57.8 \%(3,796$ of 6,751$)$, and $65.4 \%(1,848$ of 2,825$)$ at 24,36 , 


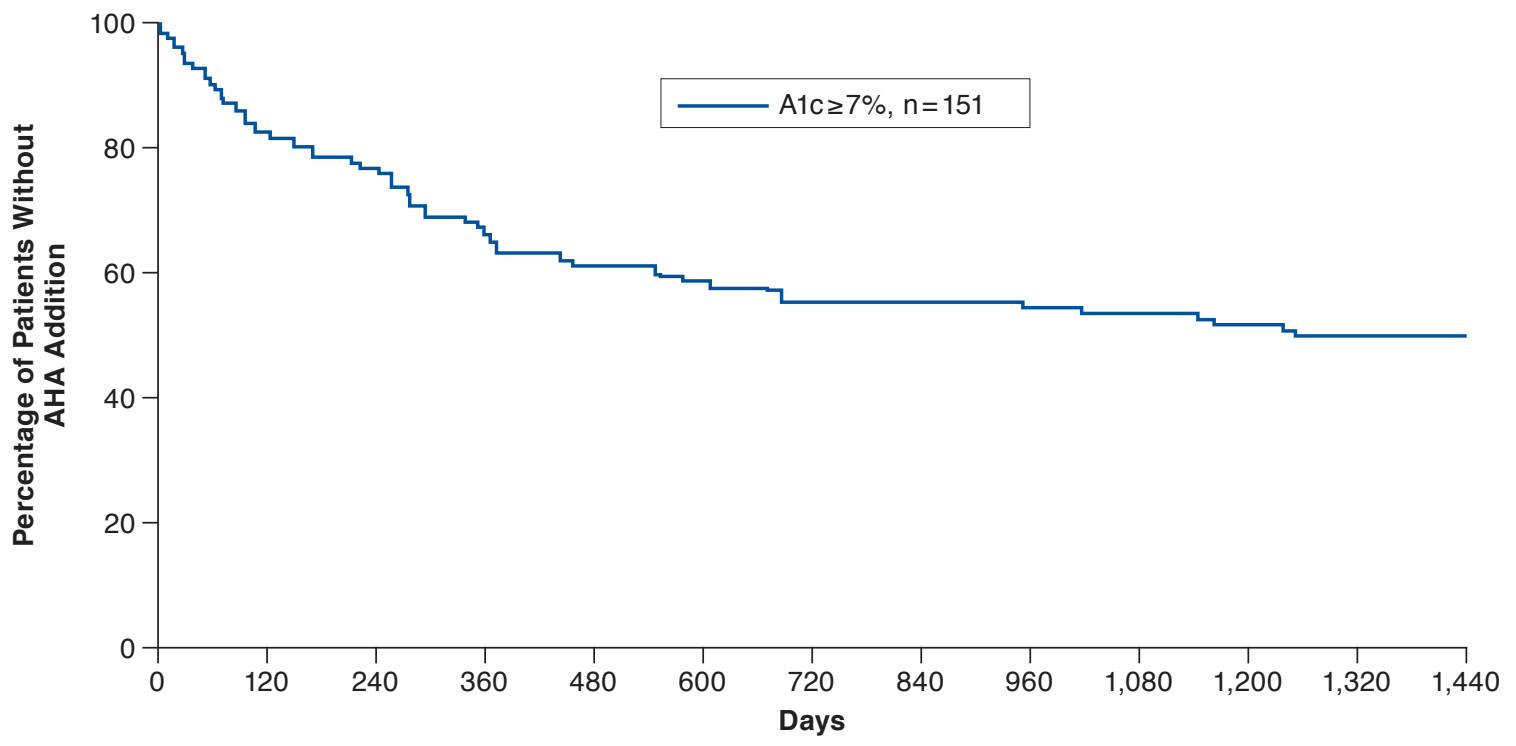

Note: Day $0=$ First elevated Alc measurement (Alc $\geq 7 \%$ ) taken within 6 months following increase in basal insulin dose.

aPoor glycemic control $=A 1 c \geq 7 \%$.

Alc = hemoglobin Alc; AHA = antihyperglycemic agent .

and 48 months post-index, among patients with 24, 36, and 48 months CE post-index, respectively.

\section{Discussion}

This retrospective real-world study is the first in the United States to investigate intensification outcomes, including titration as an intensification strategy, among T2DM patients who initiate basal insulin but remain uncontrolled. Owing to the use of linked claims and EMR data, we were able to assess changes in basal insulin dose, unlike prior studies that did not consider changes in basal insulin dose as an intensification strategy. The vast majority of patients initiating basal insulin with available 6-month Alc were uncontrolled at 6 months post-index. For these patients, the mean dose of basal insulin increased only slightly between initiation and 6 months. The 6 -month period after initiation was not effective in bringing patients to goal. The slow and insufficient up-titration indicates a reluctance among physicians and/or patients to appropriately up-titrate despite uncontrolled Alc. Calculated daily dose of insulin may overestimate prescribed daily dose; therefore, it is likely that the treatment inertia we observed occurs to an even greater extent. ${ }^{30}$

We evaluated first occurrence of treatment intensification among uncontrolled patients and included a calculated increase in basal insulin dose as a treatment intensification strategy. Most patients intensified treatment during the follow-up; however, most failed to achieve glycemic targets thereafter. The most common first treatment intensification was an increase in basal insulin dose, with dose increasing to $61.7 \mathrm{U}$ (median 38U) at the time of intensification.

However, this was not an effective strategy, as most patients who increased basal insulin dose and remained on therapy were still uncontrolled at 6 months post-intensification. Surprisingly, the majority of these patients did not add another AHA in an effort to achieve control over the follow-up. Only one third of these uncontrolled patients added another AHA in the subsequent 12 months. While a treatment goal of Alc $<7 \%$ is not appropriate for all patients, a high degree of treatment inertia was also seen via the sensitivity analysis with the use of Alc $<8 \%$ or Alc $\leq 9 \%$ as treatment goals.

\section{Treatment Intensification Barriers}

We identified a substantial unmet need for effective treatment intensification among our study sample. There is an urgent need to develop strategies to overcome clinical inertia, since delays in treatment intensification have serious clinical consequences. ${ }^{11}$

There are a number of barriers to treatment intensification. A major issue is limited awareness of clinical inertia among physicians. ${ }^{31}$ Our findings suggest that physicians should be more aware of treatment targets for users of basal insulin, as basal insulin dose is not being sufficiently titrated. Other 
barriers to treatment intensification include concerns about hypoglycemia, patient fear of side effects such as weight gain, patient resistance to complex regimens, and physician time constraints. ${ }^{31-34}$ In the secondary analysis of discontinuation of basal insulin therapy, approximately $50 \%$ of patients discontinued basal insulin within 2 years following initiation. It is possible that physicians, aware of high discontinuation rates, may be averse to intensifying therapy and increasing the perceived burden of the treatment regimen, which may influence subsequent discontinuation.

Other studies have similarly confirmed that the majority of patients treated with insulin fail to reach glycemic targets 6 months after initiation. ${ }^{21-22}$ The majority of uncontrolled patients in those studies did not intensify treatment; however, it is important to note that those studies only considered addition of an AHA as a treatment intensification strategy. ${ }^{21-25}$ A retrospective cohort study from the United Kingdom followed insulin initiators, and only $17.3 \%$ achieved Alc $<7 \%$ by 6 months post-initiation. ${ }^{21}$ The initial insulin regimen did not change for $75.1 \%$ of uncontrolled patients.

In a recent retrospective claims-based U.S. study, less than one third (30\%) of basal insulin initiators achieved Alc $<7 \%$ at 6 months post-initiation. ${ }^{22}$ A second insulin (bolus or shortacting) was prescribed to only $37.7 \%$ of uncontrolled patients. A U.S. analysis using EMR data assessed treatment intensification among patients treated with basal insulin. ${ }^{24}$ The majority (55.9\%) did not add a new AHA, and of those, $66.6 \%$ had Alc values $\geq 7 \%$.

In a claims-based U.S. study that included many Medicare Advantage patients, only $38.5 \%$ of patients had a treatment addition or switch within 90 days of Alc $\geq 9 \%$, while 38.5\% had a delayed treatment change over the 3-year follow-up. ${ }^{25}$ Another retrospective cohort study from the United Kingdom quantified the delay in treatment intensification among T2DM patients treated with basal insulin and OADs. ${ }^{23}$ Among patients with Alc $\geq 7.5 \%$, only $30.9 \%$ intensified treatment in a median of 3.7 years.

\section{Limitations}

Like any retrospective database study, the results of this study can only establish associations but not causal relationships. Administrative claims data may be limited with respect to clinical detail and accuracy as they are collected for the purpose of payment. Our study results may not be generalizable to all T2DM patients treated with basal insulin. Alc values at 6 months post-index using linked data were available for only a small proportion (1.8\%) of total basal insulin initiators.

Given the use of real-world data, it is a limitation that Alc measurements were not available at precise time points, as would be possible in a clinical trial. Not all patients have Alc measured regularly, and it is possible that patients with available Alc were more actively managed as a function of being present in the EMR database. However, demographic characteristics were similar between the overall sample and the subset with Alc (Table 1). The decision to intensify therapy could have been affected by the high prevalence of comorbid obesity among our sample, given that insulin dose is based on weight, and individuals needing higher doses of insulin gain the most weight. ${ }^{35}$

A primary care physician was most commonly associated with the basal insulin initiation. Insulin therapy requires specialist training and longer time spent with the patient compared with OAD therapy. ${ }^{31}$ Primary care physicians have limited time spent with patients, as they often manage multiple conditions simultaneously and may have less time to speak with patients specifically about their diabetes and glucose control. The study sample employed was largely commercially or self-insured and may not be representative of uninsured or Medicare or Medicaid populations.

Several limitations related to study design are also worth noting. Persistence and basal insulin dose could only be calculated based on observed prescription claims (quantity and time to next refill). Intensification of an increase in basal insulin dose increase was identified based on calculated doses. There is no reliable insight into prescribed dose for a patient from the available data sources, and it is possible that an observed increase in basal insulin dose was related to patient behaviors rather than a true intensification ordered by the physician. Alternatively, other intensification types relied on addition of another AHA, identified through new prescription fills. Further research is needed to better understand how to capture treatment intensification of an increase in basal insulin dose using claims data.

\section{Conclusions}

Our study findings suggest that a substantial unmet need for effective treatment intensification exists among patients with T2DM who are treated with basal insulin and remain in poor glycemic control. The vast majority of T2DM patients newly initiating basal insulin remained uncontrolled at 6 months following initiation. Basal insulin dose increased only slightly from date of initiation to 6 months, indicating treatment inertia. Most patients intensified treatment during the follow-up; however, insulin intensification strategies were not effective in bringing patients to goal. While patients most frequently increased basal insulin dose, most patients subsequently failed to achieve glycemic targets or add a new AHA in an effort to achieve glycemic control.

More effective, patient-centered treatment options would likely prove valuable to patients. In addition, provider education on the magnitude of treatment inertia among patients on basal insulin seems warranted. 


\section{Authors}

MICHELLE MOCARSKI, MPH, and GERMAN GUERRERO, MD, Novo Nordisk, Plainsboro, New Jersey. JASON YEAW, MPH; VICTORIA DIVINO, BA; and MITCH DEKOVEN, MHSA, QuintilesIMS, Fairfax, Virginia. JAKOB LANGER, MSc, and BRIAN LARSEN THORSTED, MSc, Novo Nordisk A/S, Soeborg, Denmark.

AUTHOR CORRESPONDENCE: Michelle Mocarski, MPH, Novo Nordisk, 800 Scudders Mill Rd., Plainsboro, NJ 08536. Tel.: 609.786.5251; E-mail:mmkc@novonordisk.com.

\section{DISCLOSURES}

This study was funded by Novo Nordisk. Mocarski, Guerrero, Langer, and Thorsted are employees and shareholders of Novo Nordisk. Yeaw, Divino, and DeKoven are employed by QuintilesIMS, which received remuneration from Novo Nordisk for work on this study.

Study concept and design were contributed by Mocarski, DeKoven, Langer, and Thorsted. Yeaw took the lead in data collection, along with Divino and DeKoven. Data interpretation was performed by Yeaw, Divino, DeKoven, and Guerrero. The manuscript was written by Mocarski and Divino and revised by Guerrero, Langer, and Thorsted, along with Yeaw and DeKoven.

Some of the data from this study were presented via poster at the AMCP Annual Meeting in March 2017 and at the 53rd EASD Annual Meeting in September 2017.

\section{REFERENCES}

1. Centers for Disease Control and Prevention. National Diabetes Statistics Report, 2017. Available at: https://www.cdc.gov/diabetes/pdfs/data/statistics/ national-diabetes-statistics-report.pdf. Accessed October 23, 2017.

2. Zhuo X, Zhang P, Hoerger TJ. Lifetime direct medical costs of treating type 2 diabetes and diabetic complications. Am J Prev Med. 2013;45(3):253-61.

3. Clar C, Barnard K, Cummins E, Royle P, Waugh N, Aberdeen Health Technology Assessment Group. Self-monitoring of blood glucose in type 2 diabetes: systematic review. Health Technol Assess. 2010;14(12):1-140. 4. American Diabetes Association. 6. Glycemic targets. Diabetes Care. 2017;40(Suppl. 1):S48-56.

5. Centers for Medicare \& Medicaid Services. Table: 33 ACO quality measures. Available at: https://www.cms.gov/Medicare/Medicare-Fee-for-ServicePayment/sharedsavingsprogram/Downloads/ACO-Shared-Savings-ProgramQuality-Measures.pdf. Accessed October 23, 2017.

6. Health Resources and Services Administration. Diabetes HbAlc \{Poor Control\}. June 11, 2012. Available at: https://www.hrsa.gov/sites/default/files/ quality/toolbox/508pdfs/diabetesmodule.pdf. Accessed October 23, 2017.

7. American Diabetes Association. 8. Pharmacologic approaches to glycemic treatment. Diabetes Care. 2017;40(Suppl. 1):S64-74.

8. American Diabetes Association. 2. Classification and diagnosis of diabetes. Diabetes Care. 2017;40(Suppl. 1):S11-24.

9. Berlowitz DR, Ash AS, Glickman M, et al. Developing a quality measure for clinical inertia in diabetes care. Health Serv Res. 2005;40(6 Pt 1):1836-53.

10. Holman RR, Paul SK, Bethel MA, Matthews DR, Neil HA. 10-year follow-up of intensive glucose control in type 2 diabetes. N Engl J Med. 2008;359(15):1577-89.

11. Paul SK, Klein K, Thorsted BL, Wolden ML, Khunti K. Delay in treatment intensification increases the risks of cardiovascular events in patients with type 2 diabetes. Cardiovasc Diabetol. 2015;14:100.

12. Stratton IM, Adler AI, Neil HA, et al. Association of glycaemia with macrovascular and microvascular complications of type 2 diabetes (UKPDS 35): prospective observational study. BMJ. 2000;321(7258):405-12.

13. Shetty S, Secnik K, Oglesby A. Relationship of glycemic control to total diabetes-related costs for managed care health plan members with type 2 diabetes. J Manag Care Pharm. 2005;11(7):559-64. Available at: http://www. jmcp.org/doi/10.18553/jmcp.2005.11.7.559.

14. Juarez D, Goo R, Tokumaru S, Sentell T, Davis J, Mau M. Association between sustained glycated hemoglobin control and healthcare costs. Am J Pharm Benefits. 2013;5(2):59-64.

15. Fu AZ, Sheehan JJ. Treatment intensification for patients with type 2 diabetes and poor glycaemic control. Diabetes Obes Metab. 2016;18(9):892-98.
16. Khunti K, Wolden ML, Thorsted BL, Andersen M, Davies MJ. Clinical inertia in people with type 2 diabetes: a retrospective cohort study of more than 80,000 people. Diabetes Care. 2013;36(11):3411-17.

17. Levin PA, Wei W, Zhou S, Xie L, Baser O. Outcomes and treatment patterns of adding a third agent to 2 OADs in patients with type 2 diabetes. J Manag Care Spec Pharm. 2014;20(5):501-12. Available at: http://www.jmcp. org/doi/10.18553/jmcp.2014.20.5.501.

18. Nichols GA, Koo YH, Shah SN. Delay of insulin addition to oral combination therapy despite inadequate glycemic control: delay of insulin therapy. J Gen Intern Med. 2007;22(4):453-58.

19. Rubino A, Mcquay LJ, Gough SC, Kvasz M, Tennis P. Delayed initiation of subcutaneous insulin therapy after failure of oral glucose-lowering agents in patients with type 2 diabetes: a population-based analysis in the UK. Diabet Med. 2007;24(12):1412-18.

20. Yu S, Schwab P, Bian B, Radican L, Tunceli K. Use of add-on treatment to metformin monotherapy for patients with type 2 diabetes and suboptimal glycemic control: a U.S. database study. J Manag Care Spec Pharm. 2016;22(3):272-80. Available at: http://www.jmcp.org/doi/10.18553/ jmcp.2016.22.3.272.

21. Blak BT, Smith HT, Hards M, Maguire A, Gimeno V. A retrospective database study of insulin initiation in patients with type 2 diabetes in UK primary care. Diabet Med. 2012;29(8):e191-98.

22. Dalal MR, Grabner M, Bonine N, Stephenson JJ, DiGenio A, Bieszk N. Are patients on basal insulin attaining glycemic targets? Characteristics and goal achievement of patients with type 2 diabetes mellitus treated with basal insulin and physician-perceived barriers to achieving glycemic targets. Diabetes Res Clin Pract. 2016;121:17-26.

23. Khunti K, Nikolajsen A, Thorsted BL, Andersen M, Davies MJ, Paul SK. Clinical inertia with regard to intensifying therapy in people with type 2 diabetes treated with basal insulin. Diabetes Obes Metab. 2016;18(4):401-09. 24. Langer J, Tian Y, Weng W, Gamble C, Mocarski M. Assessing unmet needs for type 2 diabetes patients treated with basal insulin in the United States. Poster presented at: 25th Annual Scientific and Clinical Congress (AACE), May 25-29, 2016; Orlando, FL.

25. Schwab P, Saundankar V, Bouchard J, et al. Early treatment revisions by addition or switch for type 2 diabetes: impact on glycemic control, diabetic complications, and healthcare costs. BMJ Open Diabetes Res Care. 2016;4(1):e000099.

26. Stolpe S, Kroes MA, Webb N, Wisniewski T. A systematic review of insulin adherence measures in patients with diabetes. J Manag Care Spec Pharm. 2016;22(11):1224-46. Available at: http://www.jmcp.org/ doi/10.18553/jmcp.2016.22.11.1224.

27. Charlson ME, Pompei P, Ales KL, MacKenzie CR. A new method of classifying prognostic comorbidity in longitudinal studies: development and validation. J Chronic Dis. 1987;40(5):373-38.

28. Roos LL, Stranc L, James RC, Li J. Complications, comorbidities, and mortality: improving classification and prediction. Health Serv Res. 1997;32(2):229-38.

29. Baser O, Wei W, Baser E, Xie L. Clinical and economic outcomes in patients with type 2 diabetes initiating insulin glargine disposable pen versus exenatide BID. J Med Econ. 2011;14(6):673-80.

30. Kostev K, Rathmann W. Calculated daily insulin dosages overestimate prescribed insulin doses in type 2 diabetes: a primary care database study. J Diabetes Sci Technol. 2017;11(3):597-601.

31. Khunti K, Millar-Jones D. Clinical inertia to insulin initiation and intensification in the UK: a focused literature review. Prim Care Diabetes. 2017;11(1):3-12.

32. Zafar A, Stone MA, Davies MJ, Khunti K. Acknowledging and allocating responsibility for clinical inertia in the management of type 2 diabetes in primary care: a qualitative study. Diabet Med. 2015;32(3):407-13.

33. Patel N, Stone MA, Chauhan A, Davies MJ, Khunti K. Insulin initiation and management in people with type 2 diabetes in an ethnically diverse population: the healthcare provider perspective. Diabet Med. 2012;29(10):1311-16.

34. Peyrot M, Barnett AH, Meneghini LF, Schumm-Draeger PM. Insulin adherence behaviours and barriers in the multinational Global Attitudes of Patients and Physicians in Insulin Therapy study. Diabet Med. 2012;29(5);682-89.

35. Dailey G, Admane K, Mercier F, Owens D. Relationship of insulin dose, Alc lowering, and weight in type 2 diabetes: comparing insulin glargine and insulin detemir. Diabetes Technol Ther. 2010;12(12):1019-27. 
APPENDIX Kaplan-Meier Analysis of Time from Treatment Intensification to Achievement of Alc Control: Patients with Poor Glycemic Control at 6 Months Post-Index and with Treatment Intensification ${ }^{a}$

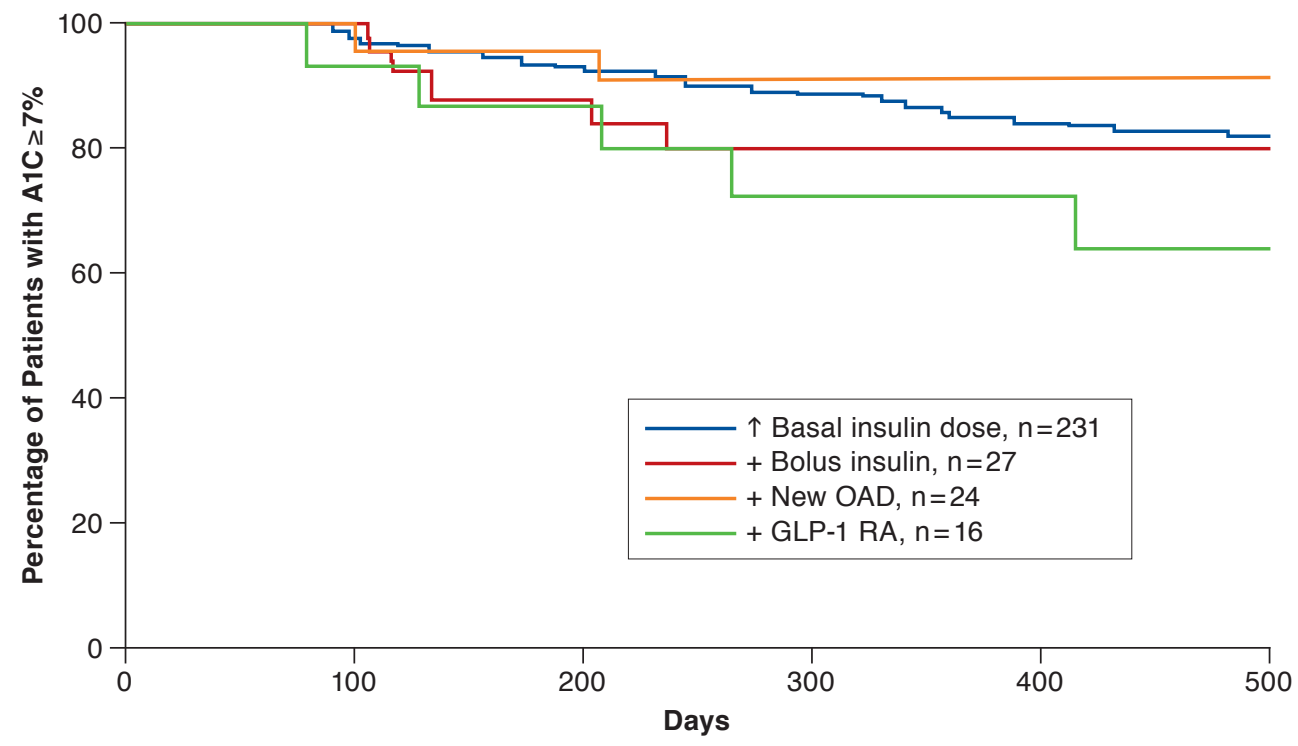

Note: Day $0=$ First elevated $A 1 c$ measurement $(A 1 c \geq 7 \%)$ taken later than 6 months after initiation of basal insulin treatment. aPoor glycemic control $=A 1 c \geq 7 \%$.

Alc =hemoglobin Alc; GLP-1 RA= glucagon-like peptide-1 receptor agonist; OAD= oral antidiabetic drug. 